\title{
Residual Need for Early Orthodontic Treatment and Orthodontic Treatment Experience among 13- to 14-Year-Old School Children in Kuwait
}

\author{
Jon Årtun ${ }^{a}$ Heidi Kerosuo $^{c}$ Faraj Behbehani ${ }^{a}$ Badreia Al-Jame ${ }^{b}$ \\ ${ }^{a}$ Department of Developmental and Preventive Sciences, Faculty of Dentistry, Kuwait University, and \\ ${ }^{b}$ Private practice, Northern Nuqra Medical Complex, Kuwait; ${ }^{\mathrm{c} D e p a r t m e n t ~ o f ~ O r t h o d o n t i c s, ~ U n i v e r s i t y ~ o f ~ T u r k u, ~}$ \\ Turku, Finland
}

\section{Key Words}

Residual orthodontic treatment need · Early

orthodontic treatment, experience

\begin{abstract}
Objective: Our purpose was to determine the residual need for early orthodontic treatment and the parameters associated with orthodontic treatment experience in 13to 14-year-old school children in Kuwait. Subjects and Methods: A total of 788 boys and 795 girls, representing about $6.7 \%$ of the target population, were selected according to cluster sampling methods. Information on nationality, family income and orthodontic treatment experience was collected through subject and family interviews. The occlusal morphology was recorded in a welllit classroom or from initial study models of subjects with orthodontic treatment experience. Results: Only $6.7 \%$ of the 225 subjects with early treatment need, defined as overjet $\geq 6.5 \mathrm{~mm}$, and functional posterior and anterior crossbite on 1 or more teeth, had treatment experience. Residual need for early treatment was present in $13.4 \%$ of the subjects. Only $26.8 \%$ of the subjects with treatment experience met our criteria for early treatment need. The odds of treatment experience were higher in the subjects attending private schools $(p<0.05)$, in those from fami-
\end{abstract}

lies with an income of KWD >2,000 (USD 6,600; $p<0.01$ ) and in subjects meeting the criteria for early treatment need ( $p<0.01$ ). Conclusions: About $15 \%$ of each birth cohort of school children in Kuwait need early orthodontic treatment. Less than $10 \%$ of those with a need have treatment experience at 13-14 years of age, and about $75 \%$ of those with treatment experience at that age do not need early treatment. The predictors for treatment experience at 13-14 years of age are private-school attendance, a high family income and need for early treatment.

Copyright $\odot 2006$ S. Karger AG, Basel

\section{Introduction}

Residual orthodontic treatment need is defined as any need that should have been met at an earlier age under ideal conditions $[1,2]$. The optimal timing of the majority of comprehensive orthodontic treatments is a 1-phase intervention in the early permanent dentition, thereby avoiding prolonged appliance wear caused merely by the incomplete eruption of premolars and canines, and reducing the potential for patient burnout [3]. At that stage any compensatory increases in the anterior segment of the dental arch have been expressed [4, 5], facilitating an appropriate extraction decision, and enough growth re-

\section{KARGER}

Fax +4161306 1234 E-Mail karger@karger.ch www.karger.com
C 2006 S. Karger AG, Basel

$1011-7571 / 06 / 0155-0343 \$ 23.50 / 0$

Accessible online at:

www.karger.com/mpp
Dr. Jon Årtun

Department of Developmental and Preventive Sciences

Kuwait University, Faculty of Dentistry

PO Box 24923, 13110 Safat (Kuwait)

Tel. +965 266 4502, ext. 7154, Fax +965 263 4247, E-Mail artun@hsc.edu.kw 
Fig. 1. Profile photos and lateral cephalograms of a patient with severe lip incompetence due to $11 \mathrm{~mm} \mathrm{OJ}$ prior to treatment (a and $\mathbf{b}$ ), and improved lip relationship after 12 months with cervical headgear and functional appliance (c and d). Note the traumatic injury to the maxillary left central incisor before treatment.
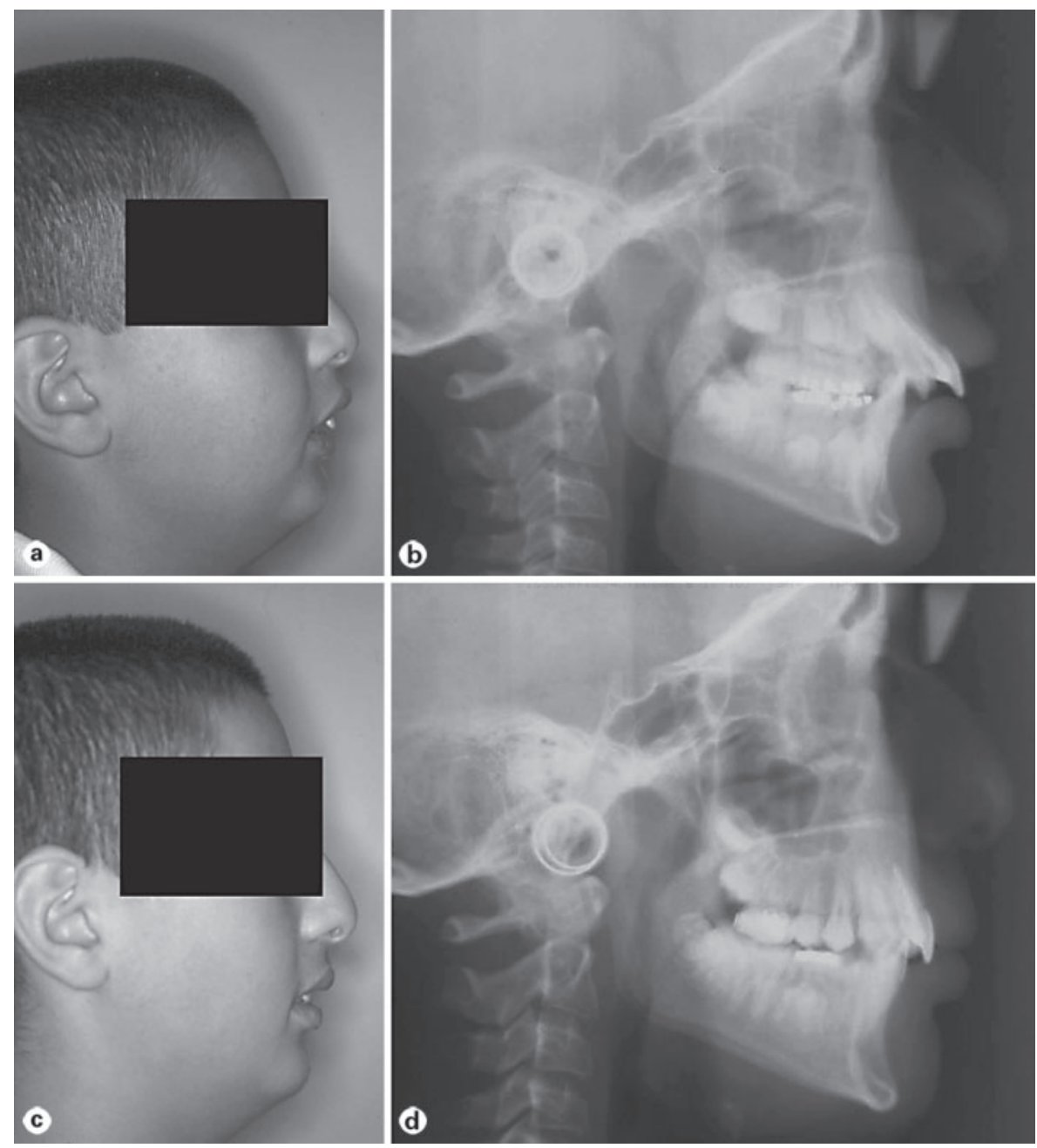

mains for successful results of growth modification strategies [6, 7]. Accordingly, any remaining need in late adolescence that does not merit surgical intervention may be considered residual $[1,2]$. Similarly, the prevalence of malocclusions in the early permanent dentition that should have been treated at earlier dental stages to reduce the potential for unfavorable development or irreversible damage may be classified as residual need for early treatment.

The effectiveness of an early Class II treatment phase is well established, resulting in major dentoalveolar changes and relatively minor improvements in the skeletal relationships [8-11]. However, a second treatment phase is typically needed in the early permanent dentition to achieve optimal morphologic results [6, 7]. Comparing the final outcome of matched Class II patient groups who have received 1- or 2-phase treatment in the early perma- nent dentition, respectively, shows that the additional early phase has no effect $[6,7]$. Neither does it reduce the proportion of complex treatments involving extractions or orthognathic surgery $[6,7]$. The only difference is a longer treatment time in the 2-phase group, making an early start less efficient and more costly [6, 7]. However, the odds of traumatic injuries to the maxillary incisors in young children are significantly increased if the overjet (OJ) is $\geq 6.5 \mathrm{~mm}$ [12-14]. In addition, an OJ of $\geq 7 \mathrm{~mm}$ has been associated with school children's reports of being teased [15]. Although inefficient, the early treatment of Class II malocclusion may therefore be justified for preventive reasons in subjects with a large OJ, provided that the aim of the first phase is limited to reducing the OJ to $\leq 6 \mathrm{~mm}$, which may frequently be achieved during a relatively short treatment period through retroclination of the maxillary incisors (fig. 1b, d). 

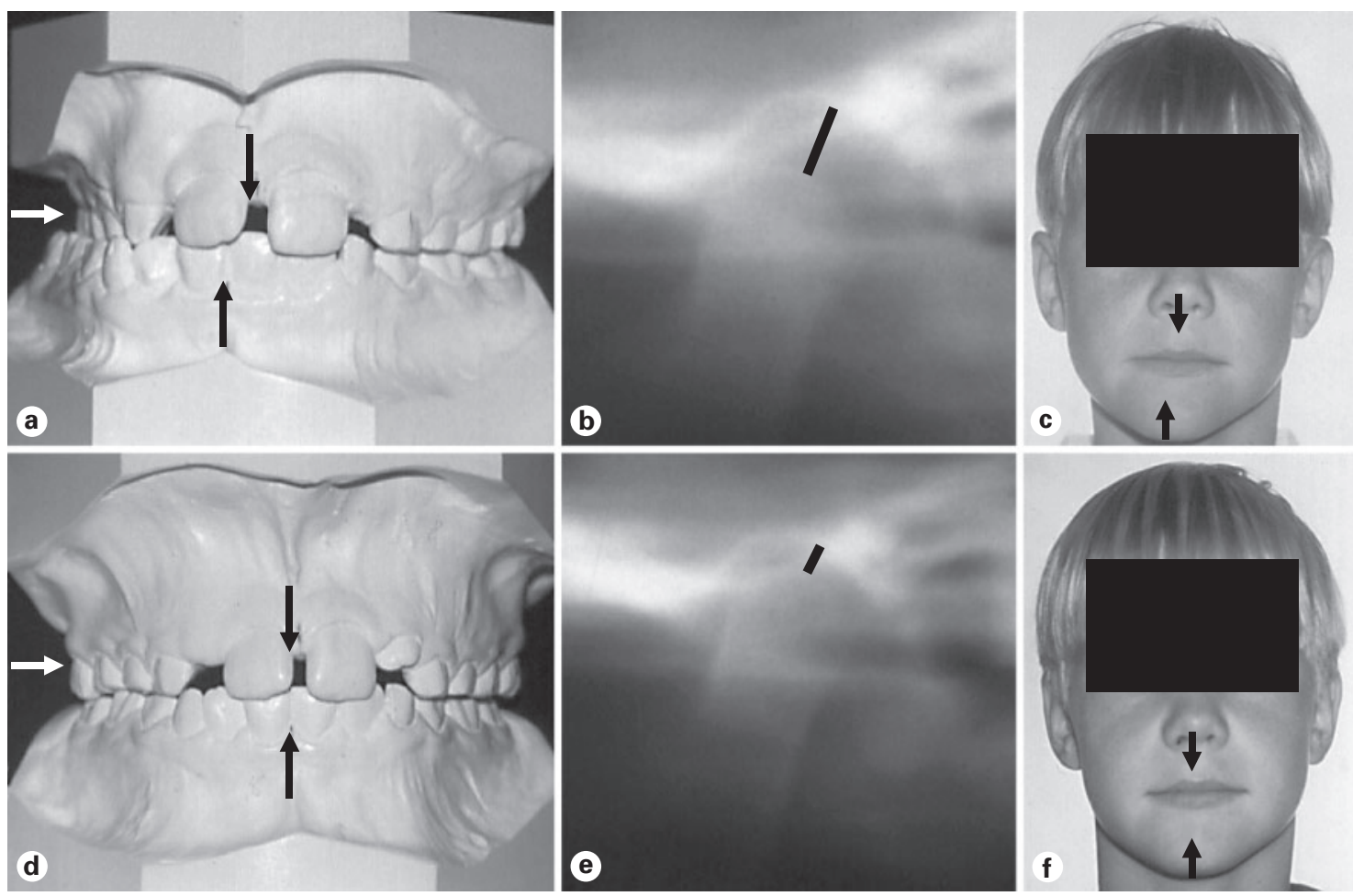

Fig. 2. Study models, tomograms of left temporomandibular joint and facial photos of a patient with unilateral posterior crossbite (a), distraction of left condyle (b) and facial asymmetry (c) in centric occlusion before treatment, and symmetric occlusion (d), normal condylar position (e) and improved facial symmetry (f) in centric occlusion after maxillary expansion.

Unilateral posterior crossbite is one of the most frequent malocclusions in the deciduous and mixed dentitions $[16,17]$, and is associated with a functional shift in about $80 \%$ of the cases $[17,18]$. As a result, an asymmetric condylar position has been documented in the maximum intercuspation, with distraction of the non-crossbite-side condyle [19, 20]. Early correction through maxillary expansion will eliminate the occlusal interferences and deviation of the mandible on closure (fig. 2a, d), resulting in a more symmetric condylar position after treatment (fig. 2b, e), and may also improve facial symmetry (fig. 2c, f) [20]. The fact that unilateral posterior crossbite is rarely associated with a functional shift in adults [21] may indicate a potential for adaptive remodeling changes of the temporomandibular joint with age and the development of a skeletal asymmetry [21, 22]. In addition, untreated unilateral crossbite may be associated with an increased risk of temporomandibular disorders [23] and a reduced bite force [24]. Typically, functional posterior crossbite can be corrected in the mixed dentition with maxillary expansion in $<4$ months, followed by a similar period of retention [20], with a high chance of posttreatment stability [25]. Early treatment of functional posterior crossbite may therefore not only be effective, but also efficient and preventive.

Patients with anterior crossbite concomitant with a functional anterior shift (fig. 3a) may experience severe attrition of the incisal edges and the incisal aspects of the labial surfaces of the maxillary incisors (fig. 3b). In addition, the anterior displacement of the condyles during function may be a predisposing factor for temporomandibular disorders [26]. Early correction can eliminate the shift during a period of about 8 months through labial expansion of the maxillary incisors [27]. The high success rate of such treatment at the 5-year follow-up [28] may therefore suggest that early treatment of pseudo-class III malocclusion is effective, efficient and preventive.

Kuwait has offered free orthodontic care to its citizens in the last few decades. The prevalence of residual treatment need in this society reflects the effectiveness of the service system to identify malocclusions in time and to provide treatments accordingly. Although a pilot study 

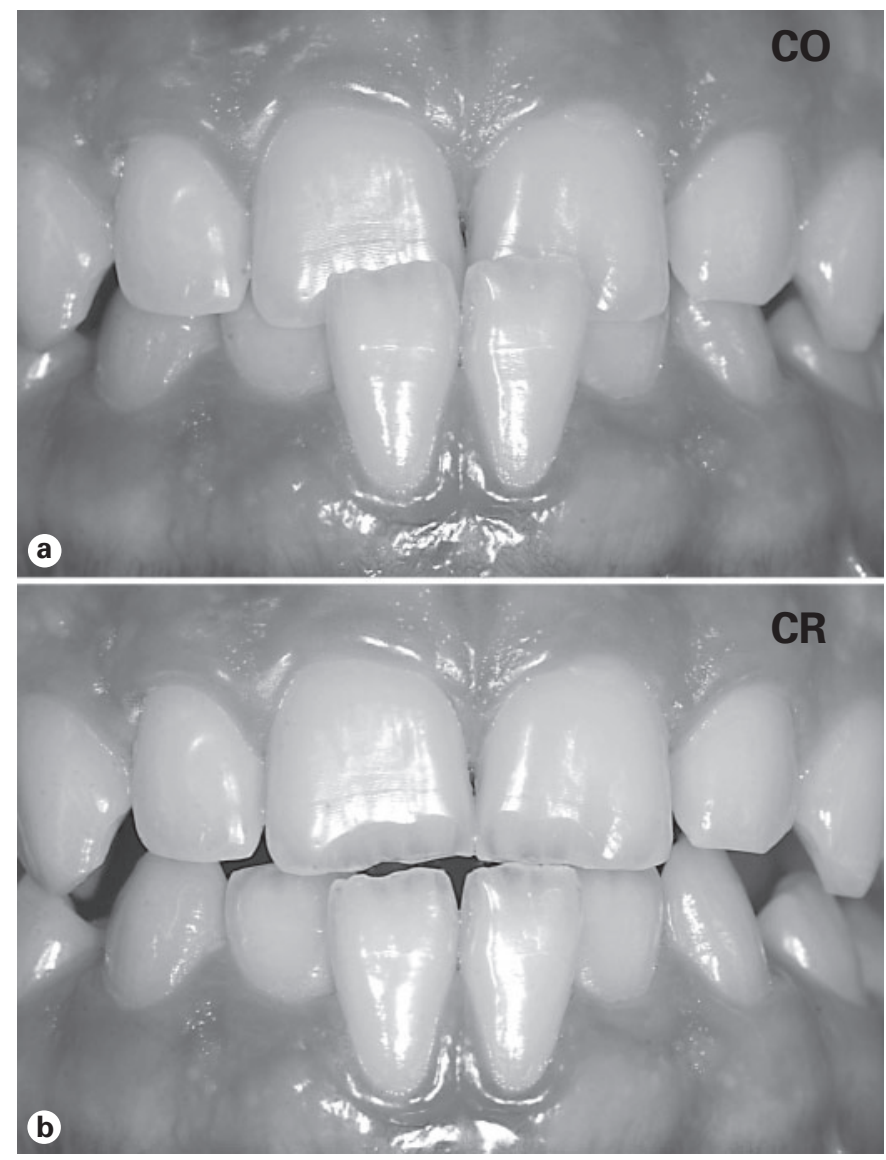

Fig. 3. Pretreatment intraoral photos of a patient in centric occlusion (a) and centric relation (b) with abrasion of maxillary incisors.

suggests that the treatment experience among Kuwaiti 8th-grade students is low [29], no information regarding the prevalence and type of early treatment is available. The purpose of this study was therefore to establish the residual need for early orthodontic treatment, defined as $\mathrm{OJ} \geq 6.5 \mathrm{~mm}$, and functional posterior and anterior crossbite on 1 or more teeth, in 13- to 14-year-old school children in Kuwait and to determine variables of significance for the decision to initiate treatment prior to that age.

\section{Subjects and Methods}

\section{Subjects}

The subjects were selected from 13- to 14-year-old school children in Kuwait according to a stratified cluster sampling method [30], defining the students in the government schools of each of the 6 administrative areas of Kuwait as 6 different strata and the students of private schools as the 7 th. The schools (clusters) from each stratum as well as the classes from each school were randomly se- lected, and the number of students to be examined from each stratum was estimated according to proportions. A total of 1,583 subjects ( 788 boys and 795 girls) of a mean age of $13.24 \pm 0.42$ years were examined, representing about $6.7 \%$ of the target population.

\section{Data Collection}

Interviews. Information on nationality and treatment history was recorded prior to the clinical examinations. Nationality was recorded as Kuwaiti, Beidoon or other non-Kuwaiti. Orthodontic treatment experience was recorded as present if active treatment was in progress, or if completion could be confirmed, with either fixed or removable appliances. Space maintenance was not recorded as orthodontic treatment. Information on total family income was collected through phone interviews with the parents and recorded as KWD $<500$ (USD 1,650), KWD 501-1,000 (USD 1,6533,300 ), KWD 1,001-2,000 (USD 3,303-6,600) and KWD $\geq 2,001$ (USD 6,603) per month.

Clinical Examinations. Permission to perform the clinical examinations during school hours was obtained from the Research Department Ministry of Education, Kuwait. A well-lit room was provided by the school principal, and the students were informed about their rights to participate. All interarch parameters were scored with the teeth in maximum intercuspal position, using gloves, mirrors and spatulas. The OJ was measured to the nearest half millimeter as the distance parallel to the occlusal plane from the incisal edge of the most labial maxillary central incisor to the most labial mandibular central incisor using a ruler. Functional posterior crossbite was scored as present if a unilateral posterior crossbite was observed on 1 or more teeth in centric occlusion (CO) and a lateral mandibular shift was detected from centric relation (CR) to CO. Similarly, functional anterior crossbite was scored as present if an anterior crossbite was observed on 1 or more incisors in $\mathrm{CO}$ and an anterior mandibular shift was detected from $\mathrm{CR}$ to $\mathrm{CO}$.

Measurements on Study Models. The subjects with treatment experience were evaluated from initial study models in $\mathrm{CO}$ position. OJ was measured as above. A unilateral posterior crossbite was scored as functional in situations with midline deviation and minimal arch asymmetry. An anterior crossbite was scored as functional if the labial and lingual surfaces of the respective incisors were in contact.

\section{Method Error}

Two sets of calibrations were performed under conditions identical to the clinical examinations that followed. In the first set each examiner investigated the same 40 subjects. Following comparison of the scores and adjustments of the criteria, another 40 subjects were seen twice about 2 weeks apart by all 4 examiners. Intra- and interclass correlation analyses were performed between the first and second scores for each examiner as well as among the 4 scores of the examiners at each of the 2 visits. The mean intraclass correlation coefficient between the first and second scores of all the examiners was 0.96 for OJ, 0.80 for posterior crossbite and 0.90 for anterior crossbite. The respective coefficients among the 4 examiners were $0.97,0.94$ and 0.97 .

\section{Data Analysis}

The number of subjects with treatment experience was calculated for the whole sample as well as by gender, nationality, area and family income. The number of subjects with need for early 
Fig. 4. Prevalence of treatment experience

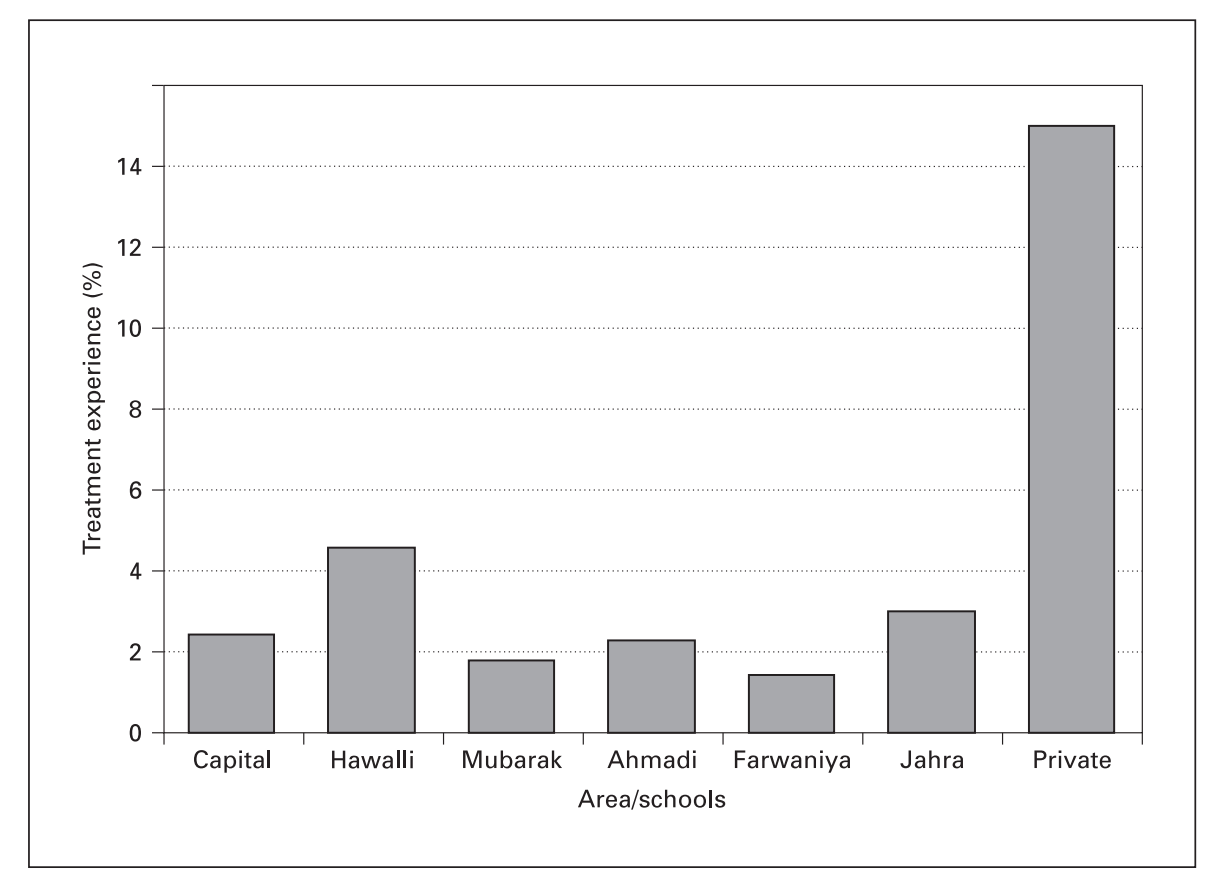

treatment (defined as presence of $\mathrm{OJ}>6.5 \mathrm{~mm}$, functional posterior and/or anterior crossbite) was calculated. Also, the number of subjects with residual need for early treatment (defined as need for early treatment without treatment experience) was determined. A $\chi^{2}$ analysis was performed to test the effect of gender, nationality, area, family income and defined the need for early treatment on treatment experience. Finally, stepwise multiple logistic regressions were employed to develop a prediction model for treatment experience. The variables were successively entered into the model if their effects were significant at $p<0.05$. At each step the variable with the lowest $p$ value was included. Previously entered variables were excluded if their effects were no longer significant $(p>0.05)$ upon inclusion of a new variable. The final model was determined when no remaining variables had a significant effect $(p>0.05)$.

\section{Results}

\section{Treatment Experience}

Only $4.2 \%$ of the 1,583 subjects had treatment experience. While treatment experience was higher $(\mathrm{p}<0.05)$ in girls $(5.3 \%)$ than in boys (3.0\%), no difference was detected between the 1,487 Kuwaitis (4.2\%) and 96 nonKuwaitis $(3.2 \%)$ in the sample $(\mathrm{p}>0.05)$. The 180 subjects attending private schools had experienced treatment more often than the 1,403 subjects attending government schools in the 6 different administrative areas $(\mathrm{p}<0.001$, fig. 4). Similarly, treatment experience was higher in the 215 subjects from families of the highest income group

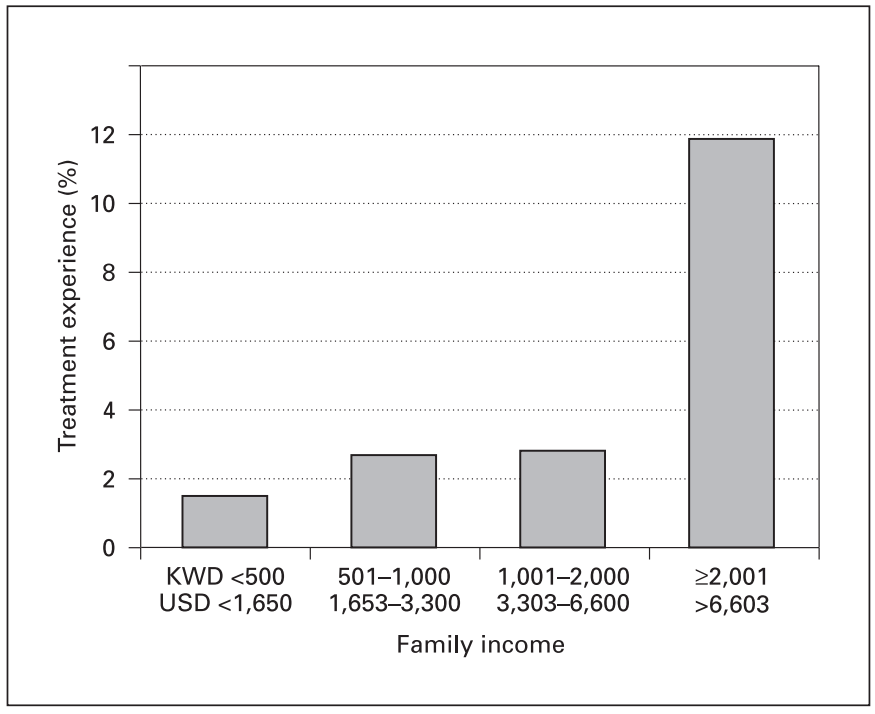

Fig. 5. Prevalence of treatment experience by family income.

than in the 1,368 subjects from families of the remaining income groups ( $p<0.001$, fig. 5).

\section{Early Treatment Need}

Initial study models of 10 subjects with treatment experience were not identified, and 1 additional subject was not scored due to human error. Of the remaining 
Table 1. Early treatment need in a population-based sample of 1,583 13- to 14-year-old Kuwaiti school children with and without orthodontic treatment experience

\begin{tabular}{|c|c|c|c|c|c|c|}
\hline & \multicolumn{2}{|c|}{$\begin{array}{l}\text { Treatment } \\
\text { experience }\end{array}$} & \multicolumn{2}{|c|}{$\begin{array}{l}\text { No treatment } \\
\text { experience }\end{array}$} & \multicolumn{2}{|l|}{ Total } \\
\hline & $\mathrm{n}$ & $\%$ & $\mathrm{n}$ & $\%$ & $\mathrm{n}$ & $\%$ \\
\hline Early treatment need & 15 & 26.8 & 210 & 13.9 & 225 & 14.3 \\
\hline No early treatment need & 41 & 73.2 & 1,306 & 86.1 & 1,347 & 85.7 \\
\hline Total & 56 & 100 & 1,516 & 100 & 1,572 & 100 \\
\hline
\end{tabular}

11 subjects were not scored, 1 without treatment experience due to human error and 10 with treatment experience due to unsuccessful location of initial study models.
Table 2. Frequency of early treatment need according to category in a population-based sample of 1,583 13- to 14-year-old Kuwaiti residents with and without orthodontic treatment experience

\begin{tabular}{lrrrrrrr}
\hline & $\begin{array}{c}\text { Treatment } \\
\text { experience }\end{array}$ & & \multicolumn{2}{c}{$\begin{array}{l}\text { No treatment } \\
\text { experience }\end{array}$} & $\mathrm{p}$ value \\
\cline { 2 - 3 } & $\mathrm{n}$ & $\%$ & & $\mathrm{n}$ & $\%$ & \\
\hline Posterior crossbite & 4 & 7.1 & & 46 & 3.0 & $<0.05$ \\
Anterior crossbite & 7 & 12.5 & & 63 & 4.2 & $<0.05$ \\
Overjet $\pm 6.5 \mathrm{~mm}$ & 4 & 7.1 & & 101 & 6.7 & $>0.05$ \\
\hline
\end{tabular}

11 subjects were not scored.

Table 3. Variables with a significant effect on treatment experience in a population-based sample of 1,583 13- to 14-year-old Kuwaiti residents

\begin{tabular}{llll}
\hline Variable & Effect $^{1}$ & Significance & Odds ratio \\
\hline Area & $0.15(0.08)$ & $\mathrm{p}<0.05$ & $1.16(1.00-1.35)$ \\
Income & $0.61(0.20)$ & $\mathrm{p}<0.01$ & $1.84(1.25-2.69)$ \\
Early treatment need & $0.82(0.32)$ & $\mathrm{p}<0.01$ & $2.27(1.22-4.23)$
\end{tabular}

\footnotetext{
${ }^{1}$ The figures in parentheses represent SE.

2 The figures in parentheses represent the confidence interval.
}

1,572 subjects the need for early treatment was identified in $225(14.3 \%$, table 1$)$. Only $15(6.7 \%)$ of the 225 subjects had treatment experience, resulting in a residual treatment need in 210 (13.4\%) of the 1,572 subjects (table 1). Of the 56 subjects with treatment experience a majority, 41 (73.2\%), had no need for early treatment. However, the frequency of early treatment need was higher $(\mathrm{p}<0.01)$ among the subjects with treatment ex- perience $(26.8 \%)$ than among those without (13.9\%, table 1). While the frequency of $\mathrm{OJ} \geq 6.5 \mathrm{~mm}$ was similar among the subjects with and without treatment experience, functional anterior and posterior crossbite occurred more often in the subjects with treatment experience $(\mathrm{p}<0.05$, table 2$)$.

\section{Predictors of Treatment Experience}

The chance of treatment experience was $16 \%$ higher for the subjects in the private than for those in the government schools and $84 \%$ higher for the subjects from families of the highest income group than for those from the remaining income groups. The odds of treatment experience were 2.27 times higher in the subjects with a presence of 1 or more of the 3 defined categories of early treatment need than for those without early treatment need (table 3).

\section{Discussion}

Unfavorable occlusal changes following premature loss of deciduous molars and extraction of first molars may be considered iatrogenic and vary according to the public administration of the preventive and therapeutic dental care programs rather than representing genuine orthodontic problems. We therefore decided to define neither impeded eruption of premolars due to mesial migration of first molars, nor tipping and rotations of molars and premolars into extraction spaces as residual orthodontic treatment need. We were unable to determine whether the early loss of deciduous second molars was due to ectopic eruption of the first molars or to caries. The lack of radiographic examination also precluded a diagnosis of supernumerary or congenitally missing teeth and tooth impactions. However, appropriate early care for the majority of such cases only includes consultation, moni- 

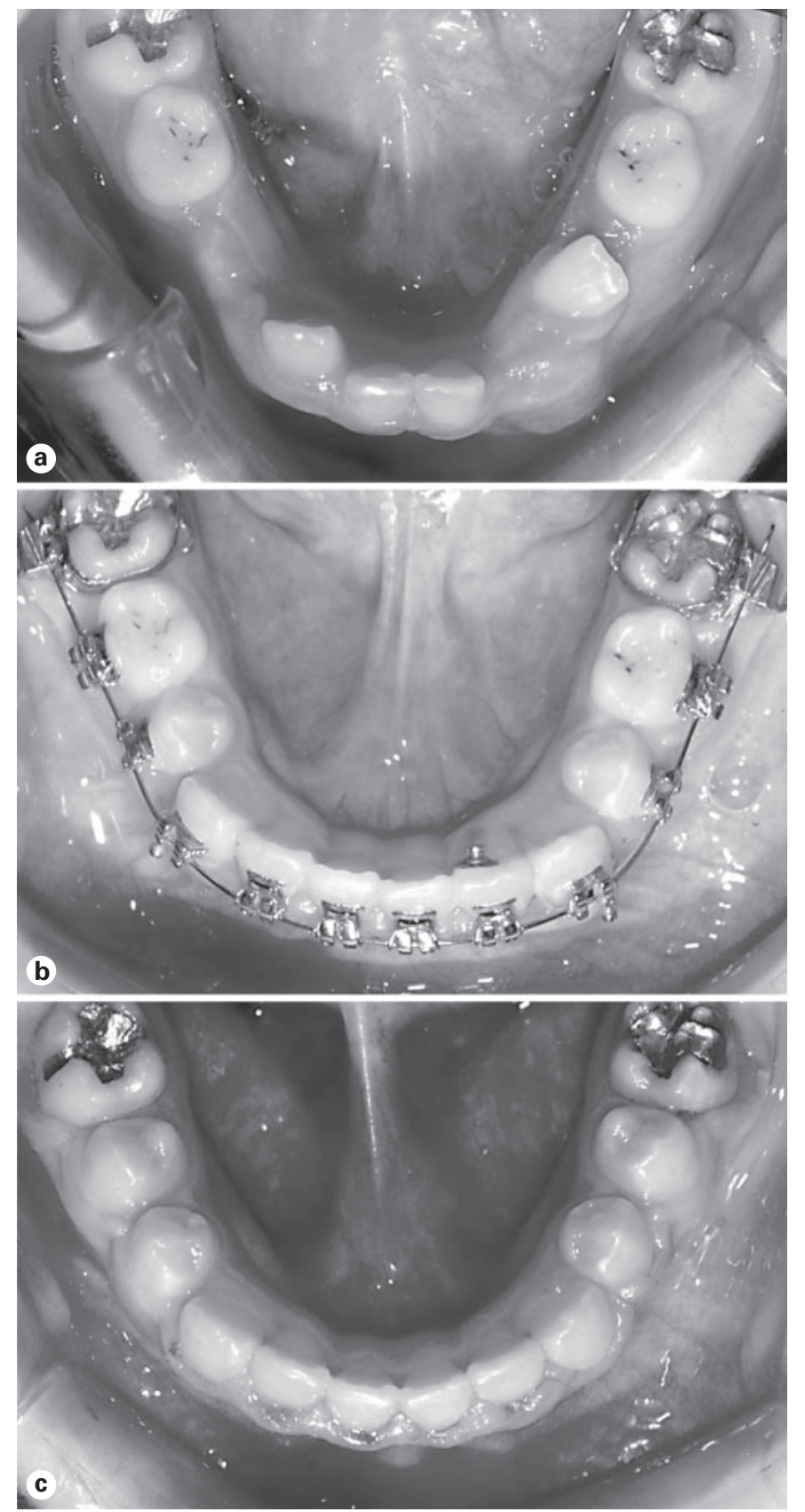

Fig. 6. Mandibular occlusal photos before treatment (a), after initial alignment (b) and at the end of treatment (c) of patients with ectopic eruption of tooth No. 32.

toring and occasional surgical intervention. The need for active orthodontic intervention may be limited to subjects with ectopically erupting first molars or incisors (fig. 6) with a minimal potential for self-alignment. Information on the prevalence of different types of dental anomalies in the Kuwaiti population is limited. However, inferences from other populations [31, 32] suggest that $<4 \%$ may need early orthodontic intervention for such reasons.

Our finding that $<7 \%$ of the subjects with a defined need for early treatment had received some orthodontic intervention prior to 13-14 years of age, resulting in a residual need for early treatment of $>13 \%$ of that age cohort, may be a concern, since orthodontic intervention is part of the public dental care program for Kuwaiti citizens. One obvious reason may be that the current employment of about 20 orthodontists by the Ministry of Health prohibits optimal orthodontic care for every annual birth cohort of $>15,000$ Kuwaitis, since about $70 \%$ have a moderate to severe malocclusion [33]. However, part of the problem may be due to insufficient planning by the health administration and a lack of awareness by the primary dental work force. Orthodontic screening according to well-defined criteria of predetermined age groups during regular examinations in the various dental clinics, followed by information for the parents, may improve the situation.

The overrepresentation of girls among orthodontic patients of this study is similar to a previous report [1]. Of the current orthodontic work force in Kuwait, about 6 are in private practice. Our findings that treatment experience was higher among subjects from families of the highest income level as well as among subjects attending private schools may therefore suggest an association between socioeconomic status and uptake of orthodontic treatment when both free and self-financed orthodontic services are available. While similar findings have been demonstrated in societies with consumer-financed orthodontic health care systems [34], the association is less clear if treatment is available at no cost $[35,36]$. In societies with publicly funded orthodontic services other factors, such as the dental visit pattern of subject and mother, general dental health and peer group experiences, may be more important [35, 36]. The exclusion of gender in the final prediction model (table 3) suggests a colinearity between female gender and 1 or more of the 3 remaining independent variables in our sample. Contrary to findings from a recent pilot study [29], we could not demonstrate any difference in treatment rate between public-school students from the urban capital area and the more rural area of Jahra. One reason may be an overrepresentation of Beidoons, who are likely to be of low socioeconomic status, among the students from Jahra in the sample of the pilot study [29]. 
Only Kuwaiti citizens are eligible under the current regulations for free orthodontic care in the respective government clinics. The remaining population is limited to exploring different self-financed, private treatment options. However, the proportion of Kuwaitis was similar among the students attending private and government schools $(p>0.05)$ as well as among students from families of the highest and the three remaining income groups $(p>0.05)$. An over-representation of Kuwaitis would have reduced the confidence in our finding that private school attendance and high family income are predictors of early treatment experience.

Our data indicate an association between defined need for early treatment and treatment experience in our sample, primarily due to a higher proportion of 1 or more teeth in functional anterior and/or posterior crossbite (table 2). We did not collect information on whether treatment was due to the subject's own initiative, parental concern or referral by the primary dentist. However, the higher proportion of functional anterior crossbite among the treated subjects may reflect a subjective desire for alignment of displaced maxillary inci- sors, since partial anterior crossbite is typically associated with severe tooth malalignment. Another possibility is the awareness of some general dentists regarding potential functional problems associated with functional shifts.

\section{Conclusions}

At least $15 \%$ of each birth cohort of Kuwaiti school children need early orthodontic treatment. Less than $10 \%$ of such children have treatment experience at 13-14 years of age, and about $75 \%$ of those with treatment experience at that age may not have need for early treatment. Predictors for treatment experience at 13-14 years of age are private-school attendance, high family income and need for early treatment.

\section{Acknowledgement}

This research was supported by Kuwait University grant No. DD07/00.

\section{References}

-1 Burden DJ, Mitropoulos CM, Shaw WC: Residual orthodontic treatment need in a sample of 15- and 16-year-olds. Br Dent J 1994;176: 220-224.

-2 Espeland L, Stenvik A: Residual treatment need in orthodontically untreated $16-$ to 20 year-olds from areas with different treatment rates. Eur J Orthod 1999;21:523-531.

3 Hsieh T-J, Pinskaya Y, Roberts WE: Assessment of orthodontic treatment outcomes: early treatment versus late treatment. Angle Orthod 2005;75:162-170.

4 Baume LJ: Physiologic tooth migration and its significance for the development of occlusion. III. The biogenesis of the successional dentition. J Dent Res 1950;29:338-348.

-5 Sillman JH: Dimensional changes of the dental arches: longitudinal study from birth to 25 years. Am J Orthod 1964;50:824-842.

-6 King GJ, McGorray SP, Wheeler TT, Dolce G, Taylor M: Comparison of peer assessment ratings (PAR) from 1-phase and 2-phase treatment protocols for class II malocclusion. Am J Orthod Dentofacial Orthop 2003;123:489496.

-7 Tulloch JF, Proffit WR, Phillips C: Outcomes of a 2-phase randomized clinical trial of early class II treatment. Am J Orthod Dentofacial Orthop 2004;125:657-667.

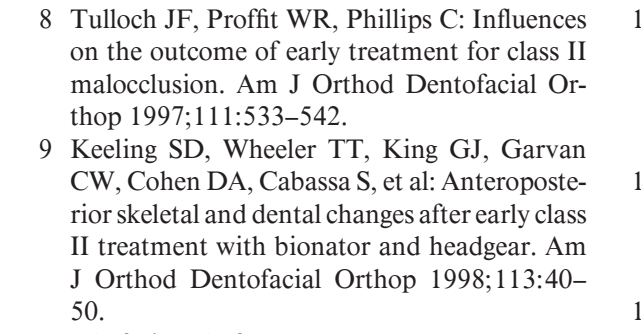

10 Ghafari J, Shofer JS, Jacobsson-Hunt U, Markowitz DL, Laster LL: Headgear versus function regulator in the early treatment of class II, division 1 malocclusion: a randomized clinical trial. Am J Orthod Dentofacial Orthop 1998; 113:51-61.

11 O'Brien KD, Wright J, Conboy F, Sanjie Y, Mandall N, Chadwick S, et al: Effectiveness of early orthodontic treatment with the Twinblock appliance: a multicenter, randomized, controlled trial. 1. Dental and skeletal effects. Am J Orthod Dentofacial Orthop 2003;124: 234-243.

12 Hunter ML, Hunter B, Kingdon A, Addy M, Dummer PM, Shaw WC: Traumatic injury to maxillary incisor teeth in a group of South Wales school children. Endod Dent Traumatol 1990;6:260-264.

13 Forsberg CM, Tedestam G: Etiological and predisposing factors related to traumatic injuries to permanent teeth. Swed Dent J 1993;17: 183-190.
14 Årtun J, Behbehani F, Al-Jame B, Kerosuo H: Incisor traumas in an adolescent Arab population: prevalence, severity and occlusal risk factors. Am J Orthod Dentofacial Orthop 2005; 128:347-352.

15 Shaw WC, Meek SC, Jones DS: Nicknames, teasing, harassment and the salience of dental features among school children. Br J Orthod 1980;7:75-80.

16 De Vis H, de Bouver JA, van Cauwenberge P: Epidemiologic survey of functional conditions of the masticatory system in Belgian children aged 3-6 years. Community Dent Oral Epidemiol 1984;12:203-207.

17 Kurol J, Berglund L: Longitudinal study and cost-benefit analysis of the effect of early treatment of posterior cross-bites in the primary dentition. Eur J Orthod 1992;14:173179.

18 Thilander B, Wahlund S, Lennartsson B: The effect of early interceptive treatment in children with posterior crossbite. Eur J Orthod 1984;6:25-34.

19 Myers DR, Barenie JT, Bell RA, Williamson $\mathrm{EH}$ : Condylar position in children with functional posterior crossbites: before and after crossbite correction. Pediatr Dent 1980;2: 190-194. 
20 Hesse KL, Årtun J, Joondeph DR, Kennedy DB: Changes in condylar position and occlusion associated with maxillary expansion for correction of functional unilateral posterior crossbite. Am J Orthod Dentofacial Orthop 1997;111:410-418.

- 21 O’Byrn B, Sadowsky C, Schneider B, BeGole $\mathrm{E}$ : An evaluation of mandibular asymmetry in adults with unilateral posterior crossbite. Am J Orthod Dentofacial Orthop 1995;107:394400.

22 Pirttiniemi P, Kantomaa T, Lahtela P: Relationship between craniofacial and condyle path asymmetry in unilateral crossbite patients. Eur J Orthod 1990;12:408-413.

23 Raustia AM, Pirttiniemi PM, Pyhtinen J: Correlation of occlusal and condyle position asymmetry with signs and symptoms of temporomandibular disorders in young adults. Cranio 1995;13:152-156.

24 Sonnesen L, Bakke M, Solow B: Bite force in pre-orthodontic children with unilateral crossbite. Eur J Orthod 2001;23:741-749.
25 Bjerklin K: Follow-up control of patients with unilateral posterior crossbite treated with expansion plates or the quad-helix appliance. $\mathrm{J}$ Orofac Orthop 2000;61:112-124.

26 Egermark-Eriksson I, Carlsson GE, Magnusson $\mathrm{T}$, Thilander B: A longitudinal study on malocclusion in relation to signs and symptoms of cranio-mandibular disorders in children and adolescents. Eur J Orthod 1990;12:399-407.

27 Gu Y, Rabie BM, Hägg U: Treatment effects of simple fixed appliance and reverse headgear in correction of anterior crossbites. Am J Orthod Dentofacial Orthop 2000;117:691-699.

28 Hägg U, Tse A, Bendeus M, Rabie BM: A follow-up study of early treatment of pseudo class III malocclusion. Angle Orthod 2004;74:465472.

29 Kerosuo H, Abdulkarim E, Kerosuo E: Subjective need and orthodontic treatment experience in a Middle East country providing free orthodontic services: a questionnaire survey. Angle Orthod 2002;72:565-570.

30 Cochran WG: Sampling Techniques, ed 3. New York, Wiley, 1977.
1 Bjerklin K, Kurol J, Valentin J: Ectopic eruption of maxillary first permanent molars and association with other tooth and developmental disturbances. Eur J Orthod 1992;14:369375 .

32 Peck L, Peck S, Attia Y: Maxillary canine-first premolar transposition, associated dental anomalies and genetic basis. Angle Orthod 1993;63:99-109.

33 Behbehani F, Årtun J, Al-Jame B, Kerosuo H: Prevalence and severity of malocclusion in adolescent Kuwaitis. Med Princ Pract 2005;14: 390-395.

34 Proffit WR, Fields HW, Moray LJ: Prevalence of malocclusion and orthodontic treatment need in the United States: estimates from the NHANES III survey. Int J Adult Orthodon Orthognath Surg 1998;13:97-106.

35 Burden DJ: The influence of social class, gender and peers on the uptake of orthodontic treatment. Eur J Orthod 1995; 17:199-203.

36 Breistein B, Burden DJ: Equity and orthodontic treatment: a study among adolescents in Northern Ireland. Am J Orthod Dentofacial Orthop 1998;113:408-413. 